Technical editor: Jackie Annis jannis@bmj.com (+44 (0)20 7383 6658)

Please note: This paper contains visible codes for electronic publishing. These will not appear in the final version and alignment of tables will be improved.

- Please check that all queries to author [in bold type and square brackets] have been answered, including those in the references and tables. Please do not renumber the references. Any additional references can be added to the bottom of the list and unwanted references deleted from the list without renumbering. The numbering will be corrected automatically during processing

\title{
Trumped again: reinstating the global gag rule
}

This unilateral action must not be allowed to derail women's right to sexual and reproductive health [suggested subtitle]

Sarah Hawkes, ${ }^{1}$ professor of global public health, Kent Buse, ${ }^{2}$ chief, strategic policy directions

${ }^{1}$ University College London, UK

${ }^{2}$ UNAIDS, Switzerland

Correspondence to: S Hawkes s.hawkes@ucl.ac.uk

There was nothing unexpected about President Trump's reinstatement of the Mexico City Policy (known as the global gag rule) in the first days of his presidency. Trump's administration is the latest in a line of American presidencies that have played fast and loose with sexual and reproductive health and rights. After the 1973 historic Roe vs Wade ruling upholding the rights of American women to decide whether or not to terminate a pregnancy, ${ }^{1}$ Senator Jesse Helms supported an amendment to the 1961 Foreign Assistance Act to ensure that no US funds could be used to pay for abortions "as a method of family planning or to motivate or coerce any person to practice abortions." 2

Variations on the Helms amendment have shuffled back and forth across the American legislature in the ensuing four decades, but the Mexico City Policy, enacted under President Reagan in 1984, proved to be the most contentious because it restricted US funding to foreign non-governmental organisations (NGOs) that provide voluntary abortion services, even if those services do not use American funds directly for abortions. ${ }^{3}$ This policy was overturned by President Clinton (1993), reinstated by President G W Bush (2001), rescinded again under President Obama (2009), and re-established by President Trump.

Trump's version, however, goes further and requires implementation of a plan "to extend the requirements of the reinstated Memorandum to global health assistance furnished by all departments or agencies." ${ }^{3}$ In other words, it potentially restricts American funding not only to foreign NGOs but to all other recipients that enable the provision of safe abortion services; this could include governments as well as the United Nations system.

Given the size of America’s health aid budget (an estimated \$13bn ( $£ 10 \mathrm{bn} ; € 12 \mathrm{bn}$ ) in 2015 , of which about $\$ 600 \mathrm{~m}$ is for family planning services ${ }^{4}$ ), the effect of extending the ban 
to any organisation that enables women to realise their right to a safe abortion could be substantial. Abortion rates rise substantially in sub-Saharan Africa whenever the Mexico City Policy is implemented. ${ }^{5}$ Since integrated family planning services also provide education on sexuality, HIV services, and a host of other sexual and reproductive health interventions, all are likely to be affected by restrictions to service delivery.

The latest ruling, however, provides an opportunity to step back from American politics and consider the global community's response to Trump's action. The following four structural changes would help ensure that the vagaries of one country's views on abortion politics no longer have such a dominating influence on the rights of women globally to make fertility choices.

Firstly, we need to end the over-reliance on single donors. The Addis Ababa action agenda on financing for development recognised the importance of diversifying funding sources to support countries with limited domestic resources. ${ }^{6}$ The Dutch government has already launched an initiative to bridge the funding gap left by the global gag rule, which includes an initial \$10m dollar commitment and a crowd funding platform for family planning and sexuality education programmes globally. The She Decides initiative has been backed by several countries and received an enthusiastic response from global citizens. [Q, is

\section{there an up to date source to cite here, directing readers to further information about} "She Decides"]

Secondly, we need to frame reproductive and sexual choices as an issue of rights. International human rights bodies have already affirmed that access to abortion is "a matter of human rights." ${ }^{7}$ Where abortion is not legal, we need to advocate to change the law and, in the interim, take the public health approach of harm reduction. ${ }^{8}$

Thirdly, we need to shift attention to all countries' obligations and their accountability for access to services. Universal in nature, this shift is clearly needed in the 40 countries in subSaharan Africa and South Asia that have been the main recipients of American funding for family planning services. ${ }^{9}$ All countries have committed to the sustainable development goals, which include target 3.7 to "ensure universal access to sexual and reproductive health and reproductive rights." ${ }^{\prime 10}$ It is time to hold countries to account for these commitmentsincluding access to family planning and, where legal, to abortion services.

One strategy for improving coverage would be to include sexual and reproductive health services within the universal health coverage framework promoted by the World Health Organization and others, and to ensure all relevant commodities are included in national 
essential medicines lists. WHO's failure to mention target 3.7 in its recent report on progress of all the other health targets in the sustainable development goals is concerning. ${ }^{11}$

Finally, we need to support and grow a global health movement based on principles of rights, justice, and equity for all. When governments fail to deliver on commitments to women's health, civil society is a powerful voice for change- but many more voices are needed.

The present debacle must motivate the broad global health community to reject a unilateral gag [Q, or “...unilateral assault on women's sexual and reproductive health”?] by the US or any other donor country [edit OK?]. It must recommit to multilateralism and to the ideals of human rights while building a broad movement that links the right to sexual and reproductive services to our common aspirations for inclusive sustainable development that leaves no one behind.

Competing interests: We have read and understood BMJ policy on declaration of interests and declare we have no competing interests. The views are those of the authors and do not necessarily reflect those of UNAIDS.

Provenance and peer review: Commissioned; not externally peer reviewed. <unknown>1 United States Supreme Court. Ruling 410 US 113 (1973)</unknown> <unknown>2 Section 104(f)(1) of the Foreign Assistance Act of 1961 (P.L. 87-195; 22 U.S.C. 2151b(f)(1)), as amended by the Foreign Assistance Act of 1973 (P.L. 93-189), approved December 17, 1973.</unknown>

<eref>3 White House. Presidential memorandum regarding the Mexico City Policy. Jan 23 2017. https://www.whitehouse.gov/the-press-office/2017/01/23/presidentialmemorandum-regarding-mexico-city-policy</eref $>$ <eref>4 Institute for Health Metrics and Evaluation. Financing global health. http://vizhub.healthdata.org/fgh/.</eref>

$<$ jrn $>5$ Bendavid E, Avila P, Miller G. United States aid policy and induced abortion in subSaharan Africa. Bull World Health Organ 2011;89:873-880C. PubMed doi:10.2471/BLT.11.091660</jrn>

<eref $>6 \quad$ United Nations. Addis Ababa Action Agenda of the Third International Conference on Financing for Development. 2015. http://www.un.org/esa/ffd/wpcontent/uploads/2015/08/AAAA_Outcome.pdf $</$ eref $>$

<eref>7 United Nations Office of the High Commissioner on Human Rights. Information series on sexual and reproductive health: Abortion. http://www.ohchr.org/_layouts/15/WopiFrame.aspx?sourcedoc=/Documents/Issues/Women/ WRGS/SexualHealth/INFO_Abortion_WEB.pdf\&action=default\&DefaultItemOpen=1</eref $>$

$<$ eref $>8$ Adams P. From Uruguay, a model for making abortion safer. New York Times 2016 Jun 28. www.nytimes.com/2016/06/28/opinion/from-uruguay-a-model-for-makingabortion-safer.html?_r=2</eref $>$

$<$ Keref $>9$ Kaiser Family Foundation. The US government and international family planning and reproductive health efforts. 2016. http://kff.org/global-health-policy/fact- 
Item: BMJ-UK; Article ID: hawkes0602;

Article Type: News; TOC Heading: Editorials; DOI: 10.1136/bmj.j654

sheet/the-u-s-government-and-international-family-planning-and-reproductivehealth/\#footnote-191159-28</eref>

$<$ eref $>10 \quad$ United Nations. Sustainable development knowledge platform.

https://sustainabledevelopment.un.org/sdg 5 </eref>

$<$ eref $>11 \quad$ WHO. Progress in the implementation of the 2030 agenda for sustainable development. Report by the secretariat. 2016.

http://apps.who.int/gb/ebwha/pdf_files/EB140/B140_32-en.pdf </eref> 